\title{
Erratum to: Clinical characteristics and outcomes of HIV-seropositive men treated with surgery for prostate cancer
}

\author{
Sudeh Izadmehr ${ }^{1,2}$ - Michael Leapman ${ }^{1,2}$ - Adele R. Hobbs ${ }^{1,2,3,4}$ - Maria Katsigeorgis ${ }^{4}$. \\ Fatima Nabizada-Pace $^{1,2} \cdot$ Seyed Behzad Jazayeri $^{4} \cdot$ David B. Samadi $^{4}$
}

Published online: 25 August 2016

(C) Springer Science+Business Media Dordrecht 2016

\section{Erratum to: Int Urol Nephrol}

\section{DOI 10.1007/s11255-016-1338-4}

In the original published version, Figure $2 \mathrm{~A}$ was incorrectly published. The correct Fig. $2 \mathrm{~A}$ is given here.

Fig. 2 Changes in Gleason score. Percentage of RALP patients that were upgraded or downgraded between biopsy and tumor removed by RALP (a). Change in Gleason score of HIV-positive prostate cancer before and after RALP (b)
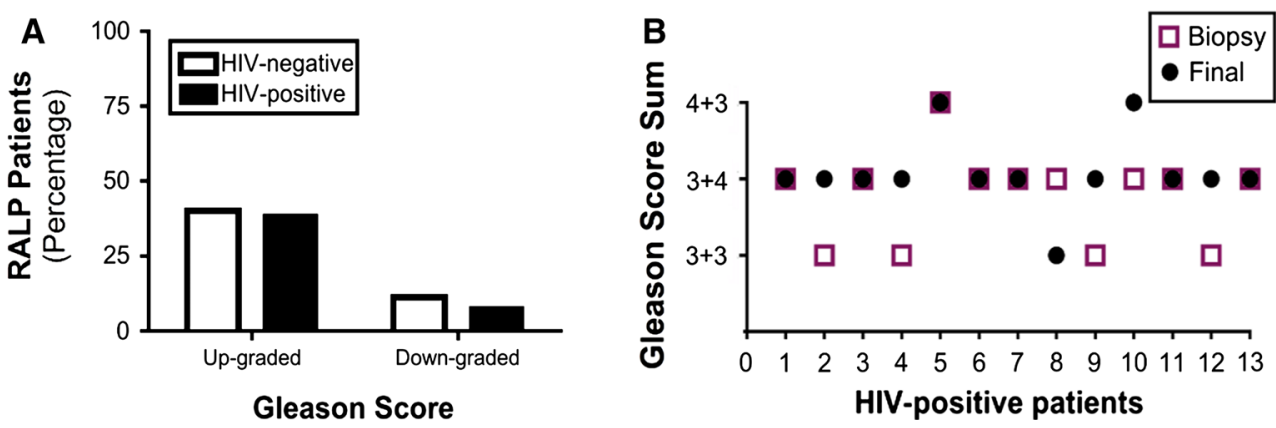

The online version of the original article can be found under doi:10.1007/s11255-016-1338-4.

David B. Samadi

robotmd@yahoo.com

1 Department of Urology, Icahn School of Medicine at Mount Sinai, New York, NY, USA

2 University of California San Francisco School of Medicine, San Francisco, CA, USA

3 Helen Diller Family Comprehensive Cancer Center, University of California San Francisco, San Francisco, CA, USA

4 Department of Urology, Hofstra Northwell School of Medicine, Lenox Hill Hospital, 485 Madison Avenue,

21 Floor, New York, NY 10022, USA 